\title{
Experimental study of acidizing diversion effect on different permeability of heterogeneity sandstone reservoirs
}

\author{
Juan $\mathrm{Du}^{1} \cdot$ Yuning $\mathrm{He}^{1} \cdot$ Pingli Liu ${ }^{1} \cdot$ Jianhua Guo ${ }^{2}$ Liqiang Zhao ${ }^{1}$
}

Received: 10 October 2018 / Accepted: 8 March 2019 / Published online: 27 March 2019

(c) The Author(s) 2019

\begin{abstract}
In the paper, the diversion laws between VES acid and heterogeneous sandstone were carried out by diversion acidizing experiments. The results showed that the viscoelastic surfactants of diversion acid reached the maximum value at hydrochloric acid concentration between 5 and $11 \%$, when higher than $13 \%$ and the diversion acid with low viscosity which was beneficial to acid injecting construction. The results of parallel core experiment revealed that diversion acid has better divert effect in the reservoir with better homogeneity, and injected acid PV of diversion acid conforms to the Darcy's law when the permeability of glass core is less than $1000 \mathrm{mD}$. From the overall results, it can be concluded that diversion acid is suitable for heterogeneous sandstone reservoirs, and the conclusion is suitable for pilot tests in oil field.
\end{abstract}

Keywords Diversion acid · Acidizing · Heterogeneity sandstone reservoir · Different permeability · Viscoelastic surfactants

\section{Introduction}

Matrix stimulation is a term given to the process conducted on a production or injection, to improve the production or injection of the well after a severe decrease in production or injection rate (Walter and Walker 1990). In this process, a chemical fluid with specific properties was injected into the targeted formation to dissolve some precipitations around the wellbore and increase permeability inside the formation. Therefore, to determine the most effective combination of acid blends and volumes for each particular reservoir, processing design and planning are often performed to ensure that the acid is placed across the entire interval (Kelland 2014). A successful diversion technique is critical to place the acid to the location where damage exists (Kelland 2014).

To improve contact of the acid solutions with the interval to be treated, one can use either mechanical or chemical placement techniques. However, mechanical technology

Pingli Liu

liupingli@swpu.edu.cn

1 School of Petroleum and Natural Gas Engineering, State Key Lab, Southwest Petroleum University, Chengdu, Sichuan 610500, People's Republic of China

2 Engineering Technology Research Institute of Southwest Oil and Gas Field Company Petro china, Chengdu, Sichuan 610017, People's Republic of China in the construction process is relatively complex and cost too much; therefore, to simplify the construction process matrix stimulations, chemical placement technique which was called diverters was usually applied in a pre-flush and temporarily plugs the zone or zones of highest permeability, allowing the main flush to react with other less permeable or more damaged zones. Chemical diversion methods (Kelland 2014), including solid particles (Williams et al. 2016), polymer gels (Coste et al. 2000; Bai et al. 2008), foams (Kapetas et al. 2015; Kam et al. 2007), viscoelastic surfactants (VESs) (Santvoort and Golombok 2015; Fink 2015), fiber (Wang et al. 2015), and so on, have been widely used in the industry.

Viscoelastic surfactants (VESs) have long been used in carbonate reservoirs to improve production and have been successfully used in most fields (Gomaa et al. 2012; AlMutawa et al. 2005). However, the application of sandstone reservoir diversion acidizing is solid particle chemical diversion methods, for example, most oilfields in China have been using benzoic acid flakes and oil-soluble resins for many years and have achieved good acidizing effect. However, due to the limited space available for offshore platforms, marine acidizing mostly adopts the unsteady column construction process, and residual acid that is returned from the formation after construction was completed and the solid particle diversion agent easily damaged the submersible electric pump. Therefore, in recent years, we have been 
always researching trials to find diversion agent suitable for sandstone reservoir matrix acidizing. Foams must be stable in the presence of the acids and the reservoir hydrocarbons, some thickened or highly viscous polymeric solutions are difficult to remove from the pores of the formation or the fracture after the operation is complete when using polymer-thickened compositions. For this purpose, field experiments were conducted using viscoelastic surfactants (VESs) in sandstone reservoirs for diversion acidizing in the Bohai oil field. Herein, erucamide propylhydroxysultaine (EH50) was chosen as the diversion acid main agent, and the parallel artificial cores were used to simulate the diverting effect of sandstone reservoirs, so as to instruct the VES sandstone reservoir diversion acidizing design.

\section{Experiment}

\section{Materials}

All of the hydrochloric acid, decane, $\mathrm{NaOH}, \mathrm{CaCl}_{2}, \mathrm{CaCO}_{3}$ and $\mathrm{NaHCO}_{3}$ were analytical reagent grade. The VES divert agent contains the erucamidopropyl hydroxysultaine (EH50) with purity of $50 \%$ and the compound corrosion inhibitor SA-1, and the EH50 amphoteric surfactant has different solubility in acid solution with the different $\mathrm{H}^{+}$concentration. Since the acid solution can cause equipment corrosion, and $1 \%$ SA-1 is added into all samples preventing the equipment corrosion during the test. The porous cores with a diameter of $50 \mathrm{~mm}$ and a length of $300 \mathrm{~mm}$ were used in this study (Santvoort and Golombok 2015), which come from sintered borosilicate glass beads with a density of $2230 \mathrm{~kg} / \mathrm{m}^{3}$. Using sintered glass cores gives a more homogenous permeability distribution and excludes adsorption effects which have been shown to alter the concentration of the VES solution (Spain et al. 2009). The length of the cores was chosen at $300 \mathrm{~mm}$ to ensure the recovery is independent of injection flow rate and the set pressure gradient is higher than the capillary pressure. Two cores with different permeability are used for each set of parallel core flow experiment. The petro-physical properties of these different cores can be found in Table 1.
First, the cores are placed in an oven $\left(190{ }^{\circ} \mathrm{C}\right)$ for $12 \mathrm{~h}$ to remove all remaining liquids from previous experiments (Santvoort and Golombok 2015). Then they are placed inside the core-holders and the sleeves are pressurized with compressed air. One of PV is defined as the sum of the pore space of both cores:

$\mathrm{PV}=\emptyset_{\text {high }} \cdot V_{\text {high }}+\emptyset_{\text {low }} \cdot V_{\text {low }}$

where $\varnothing_{\text {high }}$ and $\varnothing_{\text {low }}$ are the high- and low-permeability core porosity, respectively. $V_{\text {high }}$ and $V_{\text {low }}$ represent the bulk volume of the cores both the solid and void components. Since the cores have the same dimensions, $V_{\text {high }}=V_{\text {low }}$.

\section{Methods}

According to the Darcy formula of porous media (2), when the heterogeneous reservoir is acidified, the amount of acid in each small area is proportional to the size of its permeability (Tiab and Donaldson 2004.). After the acid is injected into the reservoir, the large amount of acid will enter into the high-permeability areas and increase the actually reservoir heterogeneity:

$Q_{i}=\frac{K_{i} \Delta P A}{\mu L}$

Apparent viscosity is the key factor that affects the acid injection and diversion during acidizing construction, and among the low viscosity acid is good for injecting sandstone reservoirs and high viscosity acid ensures that the acid is placed across the entire interval (Zhao et al. 2017). The apparent viscosity of diversion acid pumped into the formation will be reduced by porous media, so it is necessary to evaluate the shear strength of the diverting acid. Based on the experimental research on the anti-shearing of fracturing fluid, the prepared diversion acid was poured into a rotor cup of the rheology testing system and rapidly warmed to $60{ }^{\circ} \mathrm{C}$. The rotator spin speed was $170 \mathrm{~s}^{-1}$ shear rate (Petrol Ind and Stand 2005) for $30 \mathrm{~min}$ (Table 2).

A parallel core flow model for simulating heterogeneous reservoirs is established (Fig. 1). It represents a field with two layers of different permeability without crossflow ( $\mathrm{Li}$
Table 1 Sintered glass core properties

\begin{tabular}{lllllll}
\hline Core name & p.a & p.b & p.c & p.d & p.e & p.f \\
\hline Permeability $(\mathrm{mD})$ & 2200 & 1060 & 490 & 320 & 110 & 55 \\
Porosity & 0.29 & 0.32 & 0.34 & 0.36 & 0.37 & 0.38 \\
\hline
\end{tabular}

Table 2 Influences of concentration of $\mathrm{HCl}$ for viscoelastic surfactants of diverting acid

\begin{tabular}{lllllllll}
\hline$x \% \mathrm{HCl}$ & 20 & 17 & 14 & 11 & 8 & 5 & 2 & 0 \\
\hline Viscosity (mPa.s) & 3.89 & 4.35 & 7.37 & 29.65 & 59.93 & 56.82 & 6.32 & 2.31 \\
\hline
\end{tabular}


Fig. 1 Schematic of the flow experimental setup

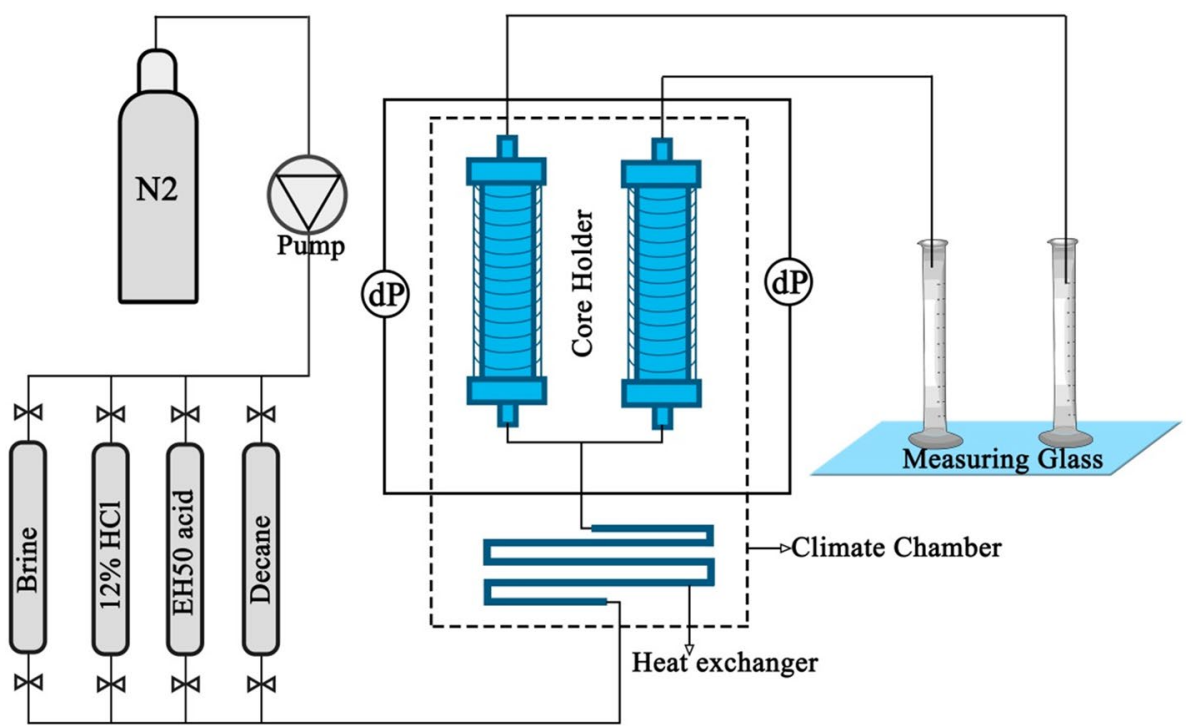

et al. 2017). Two glass cores enclosed in a rubber sleeve are placed vertically inside two stainless steel core holders.

\section{Results and discussion}

\section{Shear resistance test}

To test the shear resistance, the different rate of acid solution was prepared and this sample constitution was followed below: 1st sample $(20 \% \mathrm{HCl}+6 \% \mathrm{EH} 50)$, 2nd $(17 \% \mathrm{HCl}+6 \% \mathrm{EH} 50), 3 \mathrm{rd}(14 \% \mathrm{HCl}+6 \% \mathrm{EH} 50), 4$ th $(11 \% \mathrm{HCl}+6 \% \mathrm{EH} 50), 5$ th $(8 \% \mathrm{HCl}+6 \% \mathrm{EH} 50), 7$ th $(2 \% \mathrm{HCl}+6 \% \mathrm{EH} 50)$ and 8 th $(0 \% \mathrm{HCl}+6 \% \mathrm{EH} 50)$ acids containing different amounts of calcium carbonate powder. The rheology testing for apparent viscosity of all samples was tested by rheometer with shear rate of $170 \mathrm{~s}^{-1}$ and continued for $30 \mathrm{~min}$.

From Fig. 2, we have known that the apparent viscosity of diversion acid has an increasing trend from the hydrochloric acid concentration $20-8 \%$, and the viscosity of diversion acid increases rapidly between concentration of hydrochloric acid $13 \%$ and $8 \%$, the viscosity reaches the maximum value about $59.9 \mathrm{mPa}$.s when the concentration at $8 \%$, and then the viscosity will rapidly decline with the decrease of acid content. The viscoelastic surfactants of diversion acid reached the maximum value at hydrochloric acid concentration between 5 and $11 \%$. With the change of hydrochloric acid concentration, the change of acid viscosity means that the arrangement and distribution of EH50 in the acid liquid system have changed, and the dispersion of the acid solution and the change of micellar aggregates have been observed. Therefore, it is experimental results suggesting that the preferable concentration of hydrochloric acid injected is

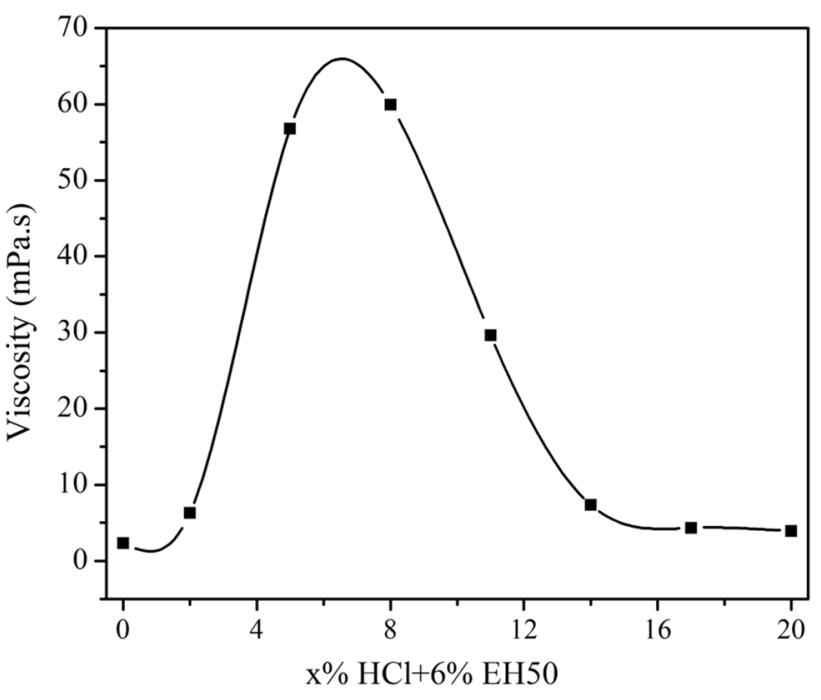

Fig. 2 Influences of concentration of $\mathrm{HCl}$ for apparent viscosity of diverting acid

$13 \% \mathrm{HCl}$ for diversion acid construction. To test the viscosity of injection, diversion and breaking of the injected acid, the viscoelastic surfactants were tested at rate of shear $170 \mathrm{~S}^{-1}$ and continued shear for $30 \mathrm{~min}\left(T=6^{\circ} \mathrm{C}\right)$ under $13 \% \mathrm{HCl}+6 \% \mathrm{EH} 50,8 \% \mathrm{HCl}+6 \% \mathrm{EH} 50,2 \% \mathrm{HCl}+6 \% \mathrm{EH} 50$ and $8 \% \mathrm{HCl}+8 \% \mathrm{EH} 50$ solutions.

In Fig. 3, the results showed that the change tendency of apparent viscosity of diversion acid with shear was stable and the change of the retention was small, indicating that the micellar system formed by $\mathrm{EH} 50$ at $60^{\circ} \mathrm{C}$ had less influence by the shear. The viscosity of $2 \% \mathrm{HCl}+6 \% \mathrm{EH} 50$ decreased slowly from 9.08 to $6.32 \mathrm{mPa}$.s during the shear time, and the viscosity of $13 \% \mathrm{HCl}+6 \% \mathrm{EH} 50$ slowly decreased from 11.09 to $8.99 \mathrm{mPa}$.s with the same trend of viscoelastic

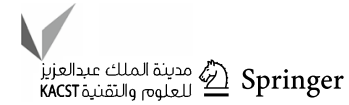




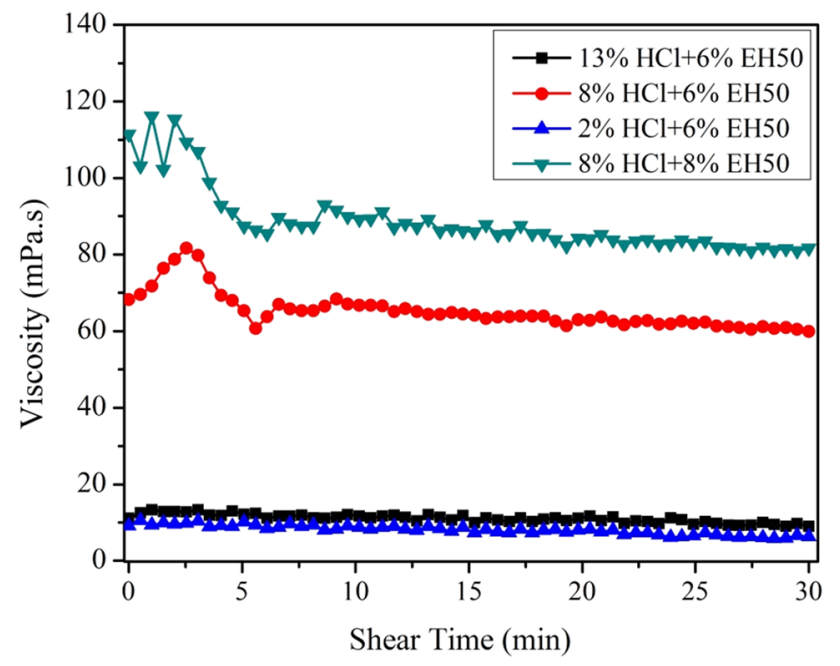

Fig. 3 The viscoelastic surfactants of the diverting acid at different concentrations $\left(T=60{ }^{\circ} \mathrm{C}\right.$, rate of shear $\left.170 \mathrm{~S}^{-1}\right)$

surfactants, suggesting the state of EH50 with low viscosity state in the solution has not appeared as micellar aggregates. However, the $8 \% \mathrm{HCl}+6 \% \mathrm{EH} 50$ and $8 \% \mathrm{HCl}+8 \% \mathrm{EH} 50$ samples showed the same tendency of viscoelastic surfactants in the shear time range and increased with the increase of surfactant concentration. The viscosity of the two acids in the first $5 \mathrm{~min}$ of shearing fluctuated greatly and then stabilized; after $30 \mathrm{~min}$ of shearing, the final viscosity of the diversion acid was $81.6 \mathrm{mPa} . \mathrm{s}$ (8\% EH50) and $59.9 \mathrm{mPa} . \mathrm{s}$ (6\% EH50) under the same conditions; the dosage of EH50 is the main factor to increase the viscosity of the turning acid. The final viscosity of $13 \% \mathrm{HCl}+6 \% \mathrm{EH} 50$, $8 \% \mathrm{HCl}+6 \% \mathrm{EH} 50$, and $2 \% \mathrm{HCl}+6 \% \mathrm{EH} 50$ after shearing for 30 min was 8.99, 59.9, and $6.32 \mathrm{mPa} . \mathrm{s}$, respectively, which the hydrochloric acid concentration was determinants of changes in diversion acid viscosity. It is all results revealed that the diversion acid was easily pumped into the reservoir under $13 \% \mathrm{HCl}+6 \% \mathrm{EH} 50,8 \% \mathrm{HCl}+6 \% \mathrm{EH} 50$ and $8 \% \mathrm{HCl}+8 \% \mathrm{EH} 50$ solutions which favor diversion acid to divert and $2 \% \mathrm{HCl}+6 \% \mathrm{EH} 50$ facilitates acid flow-back.

\section{Reservoir diversion acidification test}

For Test1 experiment, two cores with different permeability $(1060 \mathrm{mD}$ and $110 \mathrm{mD})$ were placed in core holders of parallel core, which were connected by the same inflow line and splitting the flow into two cores (Vernáez et al. 2016; Santvoort and Golombok 2015; Mahmoud et al. 2017). The pressure drop is the same for both cores, and the outflow is measured independently (Siddiqui et al. 2003; Alvarez et al. 2000; Vernáez et al. 2016). During the initial state, Brine $\left(\mathrm{CaCl}_{2}+\mathrm{NaHCO}_{3}\right.$ was applied to simulate sandstone reservoirs containing soluble hydrochloric acid) was injected into the system. And then $12 \% \mathrm{HCl}$ was injected into the system and simulated acid injection in heterogeneous sandstone reservoir. Finally, the flow rate of the liquid was recorded at the outlet of the core. The Test 2 experiment is a similar process to Test 1 , but there is more than one step where the $13 \% \mathrm{HCl}+6 \% \mathrm{EH} 50$ solution was injected into the system before injecting the $12 \% \mathrm{HCl}$ solution process.

The results shown in Fig. 4 indicate that if we do not take diversion measures in acidizing of heterogeneous sandstone reservoirs, the acid solution will flood into the high permeability zone in large quantities without any improvement in the low permeability zone, which will eventually aggravate the reservoir heterogeneity. The amount of acid that enters the low-permeability core is significantly increased, and the amount of acid entering the high-permeability core is greatly reduced when using the diversion acid, so such acidizing results can improve reservoir heterogeneity. The experiment
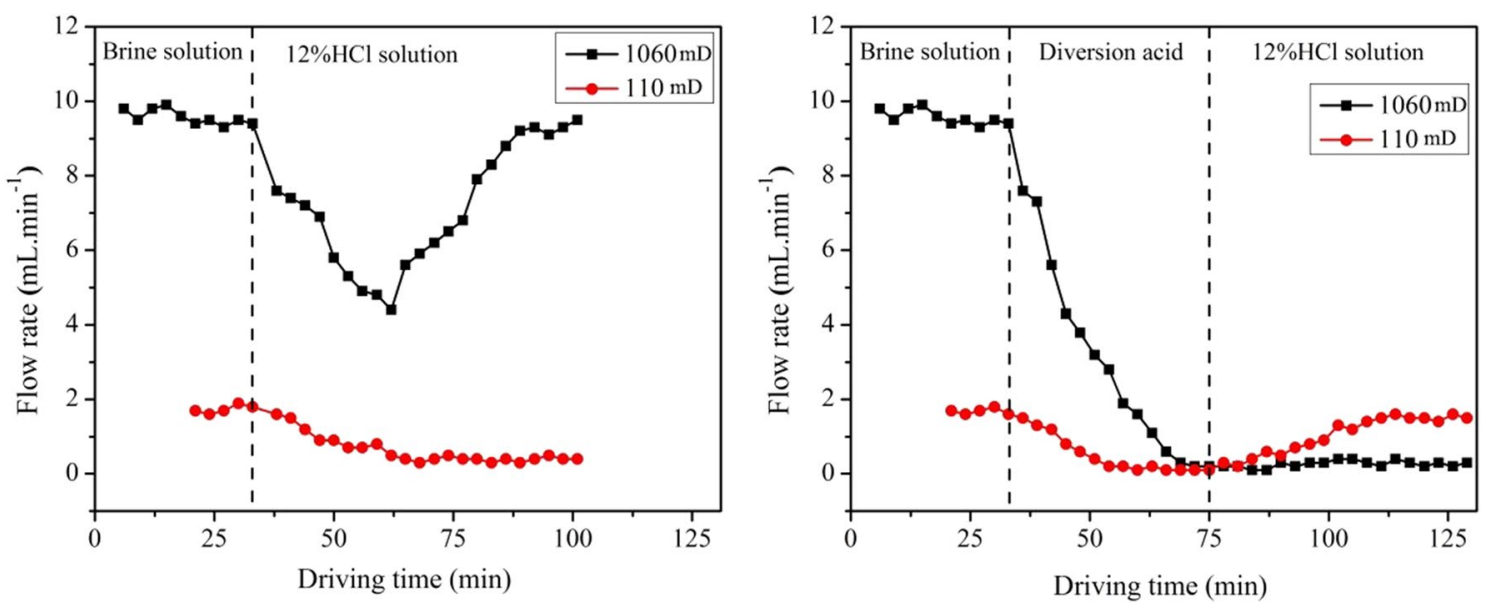

Fig. 4 Diversion effect experiment with and without EH50 (flow rate) 
also shows that the diversion acid can be used to sandstone reservoirs.

Test 3 experiment is adding the cleaned and dried the core in Test 2 experiment into core holders. During the initial state, injecting decane to saturate cores at constant flow, and brine was injected into the system until the $1060 \mathrm{mD}$ core breakthrough stop injecting (to simulate production of heterogeneous sandstone reservoir). Finally, $12 \% \mathrm{HCl}$ (containing litmus) was injected into the system until the two cores breakthrough, stop injecting, and record the volume injected at breakthrough PV (Santvoort and Golombok 2015). The Test 4 experiment has a similar steep to Test3; beside $13 \% \mathrm{HCl}+6 \% \mathrm{EH} 50$ solution was injected into the system until the pressure drop is $8 \mathrm{MPa}$ higher than beginning after brine injection process.

In Fig. 5, it can be seen that about $6.1 \mathrm{PV}$ of $12 \% \mathrm{HCl}$ solution without EH50 is required to fully sweep the $110 \mathrm{mD}$ core. During this process, most of the acid fluid flows through high-permeability core. The acid fluid can be considered as lost since it does not contribute to improve the permeability of low permeability core. During the acidizing process, a large amount of acid enters the high-permeability layers and the acidity in the low-permeability layer is very little, which finally leads to the increase of the heterogeneity of the reservoir after the acidizing. Figure 5 shows that the $\mathrm{HCl}$ acid without diversion acid was injected and entered

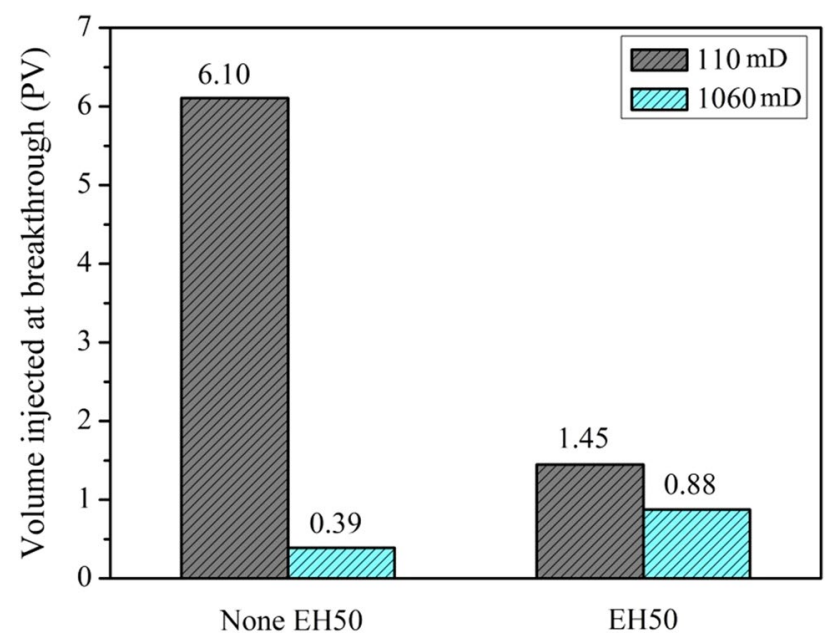

Fig. 5 Diversion effect experiment with and without EH50 (breakthrough PV) the low-permeability core, which is about $6.1 \mathrm{PV}$ of $12 \% \mathrm{HCl}$ needed. However, diversion acid has been injected before $1.45 \mathrm{PV}$ of $12 \% \mathrm{HCl}$ fresh acid was injected into the system, indicating the injected diversion acid has been placed across the entire interval, which can eventually improve the reservoir heterogeneity. This is because the diversion acid forms a viscous micelle in the high-permeability core to increase the viscous resistance and hinder subsequently acid injection.

\section{Different permeability on differences in the core of the diversion block test}

There are large differences in the permeability of heterogeneous sandstone reservoirs, so the diversion plugging experiments were designed to study different permeability differences of cores, and experimental core groups are listed in Table 3. The collected cores were cleaned and dried, loading them into the experimental device of parallel drive and injecting the saturate decane cores solution at constant flow, and then the brine with calcium chloride and sodium bicarbonate was added until the high-permeability saline core breakthrough and stopped brine injection. Under constant flow situation, the pressure and injected diversion acid was increased until the pressure of injection under 8PMa which is higher than beginning pressure, which is simulating the application of diversion acidizing at well site, and was considered the high-permeability core temporary blocking.

Figure 6 shows the diversion acid PV when parallel core achieved the diversion plugged. The $x$-axis is the permeability ratio of the parallel core and the $y$-axis is the sum of the injection volumes of the two cores [Eq. (1)]. In Fig. 6a, high-permeability 2200 experimental group with 6\% EH50 needs to inject more PV than it with $8 \%$ EH50, indicating the EH50 concentration is higher and less PV diversion acid was injected. Three sets of data from the experiment $6 \%$ EH50 show that the higher core permeability needs more PV of diverting acid to be injected. And all of data revealed that similar core permeability rate has a lower permeability, and a large difference of core permeability rate has a higher permeability, indicating with the stronger homogeneity the reservoir has a better effect on the diversion acid. The four experiment groups among Fig. 6b show that when two cores' permeability is lower than $1000 \mathrm{mD}$, closer permeability makes necessarily a higher PV to be injected to achieve diversion effect. When the permeability of high-permeability
Table 3 Diversion experiments with diversion acid on parallel core

\begin{tabular}{lllllll}
\hline Samples & \multicolumn{2}{l}{ High-low permeability $(\mathrm{mD})$} & Diversion acid \\
\hline 1 & $2200-55$ & $2200-110$ & $2200-320$ & $2200-490$ & $2200-1060$ & $13 \% \mathrm{HCl}+8 \%$ EH50 \\
2 & $2200-55$ & $2200-110$ & $2200-320$ & $2200-490$ & $2200-1060$ & $13 \% \mathrm{HCl}+6 \%$ EH50 \\
3 & $1060-55$ & $1060-110$ & $1060-320$ & $1060-490$ & & $13 \% \mathrm{HCl}+6 \% \mathrm{EH} 50$ \\
4 & $490-55$ & $490-110$ & $490-320$ & & & $13 \% \mathrm{HCl}+6 \% \mathrm{EH} 50$ \\
\hline
\end{tabular}


Fig. 6 a PV different diversion PV with different permeability. b Different diversion PV with different permeability (6\% EH50)
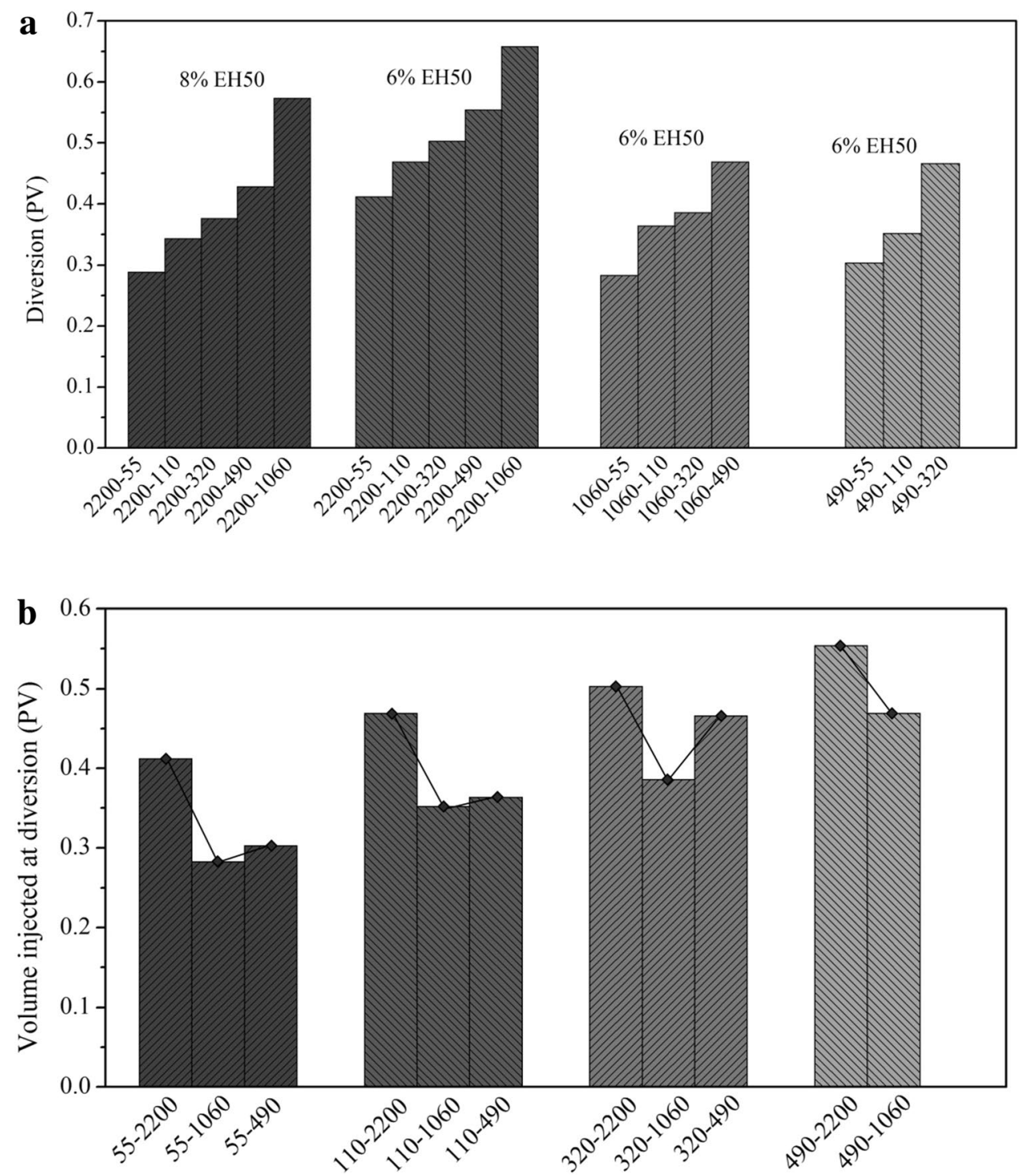

core is higher than $1000 \mathrm{mD}$, the greater injected acid PV was demanded to achieve the diversion effect.

\section{Mechanism analysis on VES-EH50 diversion acid in sandstone}

EH50 is an amphoteric surfactant and its molecular structure is shown below. When the concentration of $\mathrm{H}^{+}$in the acid solution is too high, EH50 shows the property of cationic surfactant. At the same time, the $\mathrm{H}^{+}$in the acid solution will repulse the cationic surfactant, which makes EH50 to aggregate only in the form of dispersed micelles. With the gradual consumption of $\mathrm{H}^{+}$in acid solution, EH50 shows the properties of amphoteric surfactants, and $\mathrm{H}^{+}$will gradually reduce its repulsion toward the carboxylate groups in EH50. In this process, the EH50 will gradually aggregate into large worm-like micelles, thereby increasing the viscosity of the diversion acid.
According to Darcy law, the flow through the different cores is proportional to the permeability of the core when the fluid flows through the parallel core. Therefore, the closer the permeability of the two cores the closer the flow of fluid through two cores is during fluid flow. That is not obvious when the diversion acid is used on reservoirs with better homogeneity. When core permeability is lower than $1000 \mathrm{mD}$, the permeability of the two cores is closer and the more PV was injected, and the permeability of high-permeability core is higher than $1000 \mathrm{mD}$, with the increasing of permeability of high-permeability core and the more PV also was needed to be injected. It is indicated that the capillary effect will influence the injection of acid, and the lower core permeability and the greater impact of capillary forces. Therefore, the capillary force has a less impact on injection acid when the core permeability is more than $1000 \mathrm{mD}$. 


\section{Conclusions}

In summary, EH50 was considered as diversion acidizing agent which was applied to heterogeneous sandstone reservoirs by the diversion experiment. From this work, it can be conclude the following:

1. The final viscosity of $13 \% \mathrm{HCl}+6 \% \mathrm{EH} 50$, $8 \% \mathrm{HCl}+6 \% \mathrm{EH} 50$ and $2 \% \mathrm{HCl}+6 \% \mathrm{EH} 50$ at rate of shear $170 \mathrm{~S}^{-1}$ and continuing shear for $30 \mathrm{~min}$ $\left(T=60^{\circ} \mathrm{C}\right)$ was $8.99,59.9$ and $6.32 \mathrm{mPa}$.s, respectively. The concentration of $\mathrm{HCl}$ is the dominating factor of viscosity change of EH50 diversion acid. The viscoelastic surfactants of diversion acid reached the maximum value at hydrochloric acid concentration between 5 and $11 \%$.

2. In parallel core experiment with or without diversion acid process, the large amount of acids will flow through the high-permeability core when no diversion measures are taken. After the diversion measures are taken, the acid solution will flow through the heterogeneous core more evenly.

3. When the diversion acid fluid flows through the parallel core, the permeability of core is more similar and the flow between cores is more close which will have less effect on well homogeneity reservoir. And the capillary phenomenon will influence the injection of acid, and the lower core permeability and the greater impact of capillary forces.

The overall results suggested that diversion acid can be applied to the heterogeneous sandstone reservoir and is suitable for pilot tests in oil fields.

Acknowledgements This work was supported by the Open Fund (2016ZX05058-003) of high efficiency oil production engineering and supporting technology demonstration in Bohai Oilfield.

Open Access This article is distributed under the terms of the Creative Commons Attribution 4.0 International License (http://creativeco mmons.org/licenses/by/4.0/), which permits unrestricted use, distribution, and reproduction in any medium, provided you give appropriate credit to the original author(s) and the source, provide a link to the Creative Commons license, and indicate if changes were made.

\section{References}

Al-Mutawa M, Al-Anzi EHD, Jemmali M, Chang FF, Samuel E, Samuel MM (2005) Zero damaging stimulation and diversion fluid: field cases from the carbonate formations in North Kuwait. Spe Prod Facil 20(2):94-105

Alvarez JM, Rivas H, Navarro G (2000) An optimal foam quality for diversion in Matrix-acidizing projects. Paper SPE 58711. In: Proceedings of SPE international symposium on formation damage control. Lafayette, Lousiana. February 23-24
Bai B, Huang F, Liu Y, Seright RS, Wang Y (2008) Case study on prefromed particle gel for in-depth fluid diversion. In: SPE symposium on improved oil recovery, Tulsa, Oklahoma, USA, 20-23 April. Society of Petroleum Engineers. https://doi. org/10.2118/113997-MS

Coste JP, Liu Y, Bai B, Li Y, Shen P, Wang Z, Zhu G (2000) In-depth fluid diversion by pre-gelled particles. Laboratory study and pilot testing. In: SPE/DOE improved oil recovery symposium, Tulsa, Oklahoma, 3-5 April. Society of Petroleum Engineers. https://doi. org/10.2118/59362-MS

Fayzi P, Mirvakili A, Rahimpour MR, Farsi M, Jahanmiri A (2015) Experimental study of alcoholic retarded acid systems for high temperature gas wells acidizing process. Chem Eng Res Design 93:576-583

Fink J (2015) Petroleum engineer's guide to oil field chemicals and fluids, 2nd edn. Gulf Professional Publishing, Waltham

Fredd CN, Fogler HS (1998) The kinetics of calcite dissolution in acetic acid solutions. Chem Eng Sci 53(22):3863-3874

Gomaa AM, Cutler J, Qu Q, Cawiezel K (2012) Acid placement: an effective VES system to stimulate high-temperature carbonate formations. In: SPE international production and operations conference \& exhibition, Doha, Qatar, 14-16 May. Society of Petroleum Engineers. https://doi.org/10.2118/157316-MS

Kam SI, Frenier WW, Davies SN, Rossen WR (2007) Experimental study of high-temperature foam for acid diversion. J Pet Sci Eng 58(1):138-160

Kapetas L, Bonnieu SV, Farajzadeh R, Eftekhari AA, Shafian SRM, Bahrim RZK et al (2015) Effect of permeability on foam-model parameters: an integrated approach from core-flood experiments through to foam diversion calculations. In: Ior 2015 -, European symposium on improved oil recovery (Vol. 530)

Kelland MA (2014) Production chemicals for the oil and gas industry, second edition. Crc Press, Boca Raton

Li S, Wang Z, Xu X, Zheng R, Hou J (2017) Experimental study on dissociation of hydrate reservoirs with different saturations by hot brine injection. J Nat Gas Sci Eng 46:555-562

Mahmoud M, Barri A, Elkatatny S (2017) Mixing chelating agents with seawater for acid stimulation treatments in carbonate reservoirs. J Pet Sci Eng 152:9-20

Petrol Ind Stand (2005) Chinese standard for petroleum industry SY/T 5107-2005, Recommended practice on measuring the properties of water-based fracturing fluid. Petroleum Industry Press, Beijing

Santvoort JV, Golombok M (2015) Viscoelastic surfactants for diversion control in oil recovery. J Pet Sci Eng 135:671-677

Siddiqui S, Talabani S, Yang J, Saleh ST, Islam MR (2003) An experimental investigation of the diversión characteristics of foam in Berea sandstone cores of contrasting permeabilities. J Pet Sci Eng 37:51-67

Spain D, Troost S, Golombok M (2009) Shear induced structure additives and nonlinear pressure drop effects in permeable flow. J Colloid Interface Sci 338:261-265

Tiab D, Donaldson EC (2004) Chapter 3-porosity and permeability. petrophysics. Elsevier Inc, Amsterdam

Vernáez O, García A, Castillo F, Ventresca ML, Müller AJ (2016) Oilbased self-degradable gels as diverting agents for oil well operations. J Pet Sci Eng 146:874-882

Walter RD, Walker ML (1990) Compositions and method for controlling precipitation when acidizing sour wells, US patent US19890320655, 21 Aug 1990

Wang D, Zhou F, Ge H, Shi Y, Yi X, Xiong C et al (2015) An experimental study on the mechanism of degradable fiber-assisted diverting fracturing and its influencing factors. J Nat Gas Sci Eng $27: 260-273$

Williams V, Mccartney E, Nino-Penaloza A (2016) Far-field diversion in hydraulic fracturing and acid fracturing: using solid particulates

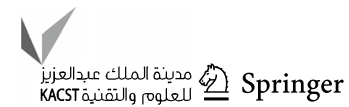


to improve stimulation efficiency. In: SPE Asia Pacific hydraulic fracturing conference

Zhao X, Guo J, Peng H, Pan R, Aliu AO, Lu Q et al (2017) Synthesis and evaluation of a novel clean hydraulic fracturing fluid based on star-dendritic polymer. J Nat Gas Sci Eng, 43:179-189
Publisher's Note Springer Nature remains neutral with regard to jurisdictional claims in published maps and institutional affiliations. 